\title{
Effects of Two Different Cyclic Heat Treatments on Microstructure and Mechanical Properties of Ti-V Microalloyed Steel
}

\author{
Zheng Lv ${ }^{a *}$, Xue-ping Ren ${ }^{a}$, Zhi-hong $\mathrm{Li}^{b}$, Zi-ming Lü, Min-min Gao ${ }^{a}$ \\ ${ }^{a}$ School of Materials Science and Engineering, University of Science and Technology Beijing, \\ Beijing 100083, China \\ ${ }^{b}$ Department of Materials Engineering, Sichuan Engineering Technical College, Deyang 618000, China
}

Received: June 12, 2014; Revised: February 8, 2015

\begin{abstract}
In this work the effects of two different cyclic heat treatments (traditional route and new-designed route, named as Route 1 and Route 2, respectively) on microstructure and mechanical properties of Ti-V microalloyed steel were investigated. The results showed that the mean grain size initially decreased on execution of 1-cycle $(\sim 13.9 \mu \mathrm{m})$ and then remained almost constant during the subsequent cycles for Route 1. By contrast, the mean grain size decreased continuously with cyclic numbers and reached $\sim 4.6 \mu \mathrm{m}$ at 7-cycle for Route 2. For Route 1, with cyclic numbers UTS decreased continuously and $\mathrm{A}_{\mathrm{KU}}$ kept fluctuating due to the accumulation effect of temper softening and continuous fluctuation of $\mathrm{RD}$ (relative differences of grain sizes), respectively. For Route 2, the continuing decline of UTS with cyclic numbers could be ascribed to the increase of mean complex carbide size, while the $\mathrm{A}_{\mathrm{KU}}$ underwent a process of increasing and then decreasing with cyclic numbers and reached the maximum $(\sim 183 \mathrm{~J})$ at 3-cycle as a result of joint influence of mean grain size and proeutectoid ferrite proportion.
\end{abstract}

Keywords: cyclic heat treatment, Ti-V microalloyed steel, grain refinement, complex carbides, mechanical properties

\section{Introduction}

Quenched and tempered steel has relatively good proportion between yield strength and toughness due to fine dispersion of ferrite-cementite mixture ${ }^{1}$. The finer the previous austenite grain is, the better the mechanical properties of quenched and tempered steel will be. One of the effective methods of the previous austenite refinement is refinement by temperature cycling, i.e., by cyclical repeated heating and cooling of steel ${ }^{2}$. The various noble microstructural changes and their effects on process kinetics and material properties have established the potential of cyclic (repeated) heat treatment techniques in recent years ${ }^{3}$. The main method used for refinement is the thermomechanical processing such as extrusion or forging of powders or ingots. However, all these methods induce significant difficulty in experimentation and thus considerable cost in production ${ }^{4}$. The cyclic heat treatment achieves the grain refinement without thermomechanical processing and thus reduces the difficulty and cost in experimentation. Therefore, the cyclic heat treatment based on quenching and tempering could be regarded as an optimal method for improvement of comprehensive mechanical properties of steels.

The microalloyed steels have a fine combination of strength and toughness. Usually, depending on the microalloying element, two different routes are presented to get the desired mechanical requirements: austenite grain size refinement and precipitation strengthening ${ }^{5}$. Therefore, for Ti-V microalloyed steel without any form of deformation, the effects of quenching and tempering process on types, density and size of precipitates should be emphatically considered.

*e-mail: lvzheng1988@126.com

The appropriate cyclic temperature and time could not only guarantee sufficient solid solution content of alloy elements, but also avoid the deterioration of pinning effect caused by precipitates coarsening. The previous works on microalloyed steels mainly focused on the precipitation of carbonitride, dynamic recrystallization behavior and microstructural evolution during deformation process ${ }^{6-8}$.

Traditional route of cyclic heat treatment involves pretreatment and repeated quenching \& tempering. This process is very complicated mainly reflected on the amount of equipment and actual operation time due to the alternating heat treatment temperature. Furthermore, the improvement of mechanical properties is limited by traditional route. New-designed route of cyclic heat treatment proposed in this work consists of three stages: pretreatment, continuous quenching and final tempering. With respect to the traditional route, new-designed route takes advantages of less equipment and operation time. It's noteworthy that a 'dual structure' of tested steel causing $\mathrm{A}_{\mathrm{KU}}$ nearly doubled (at 3-cycle) were induced through new-designed route. In this work, the microstructural evolution, refinement mechanisms and mechanical properties of Ti-V microalloyed steel subjected to two different heat treatments were investigated in details.

\section{Material and Methods}

The chemical composition of as-cast Ti-V microalloyed steel used in this work is given in Table 1. The billets for metallographic examination and mechanical tests were cut from as-cast ingot using electro-discharge machining (EDM), 
and then subjected to cyclic heat treatment for different number of cycles, viz. 1-cycle, 2-cycle, 3-cycle, 4-cycle and 7-cycle, respectively. The two cyclic heat treatment routes (traditional route and new-designed route, named as Route 1 and Route 2, respectively) are illustrated in Figure 1 in details. Both two routes consisted of two parts: pretreatment \& cycle procedure. For Route 1, pretreatment was comprised of solution treatment $\left(960^{\circ} \mathrm{C}, 30 \mathrm{~min}\right)$ and tempering $\left(570{ }^{\circ} \mathrm{C}, 40 \mathrm{~min}\right)$, while the cycle procedure included repeated short-duration quenching $\left(960^{\circ} \mathrm{C}, 5 \mathrm{~min}\right)$ $\&$ tempering $\left(570{ }^{\circ} \mathrm{C}, 40 \mathrm{~min}\right)$. For Route 2, pretreatment was comprised of solution treatment $\left(960^{\circ} \mathrm{C}, 30 \mathrm{~min}\right)$ and normalizing $\left(960^{\circ} \mathrm{C}, 5 \mathrm{~min}\right)$, while cycle procedure included continuous quenching $\left(870{ }^{\circ} \mathrm{C}, 5 \mathrm{~min}\right)$ whose numbers correspond to cyclic numbers and a final tempering $\left(570^{\circ} \mathrm{C}\right.$, $40 \mathrm{~min}$ ). In addition, except the air cooling for normalizing within Route 2, all remaining cooling processes were achieved by oil cooling for both routes.

The metallographic specimens were prepared for microstructure determination using a metallurgical microscopes (ZEISS AxioCamMR5, Germany). Some of these were eroded by saturated aqueous solution of picric acid in water bath at $60{ }^{\circ} \mathrm{C}$ to show the grain boundaries, and the rest were etched by $4 \%$ NITAL to show their current microstructure. The grain sizes were measured as ASTM E112 standard. To investigate the grain refinement mechanism for Route 2, the metallographic specimens were further examined in a Field-emission Scanning Electron Microscope (ZEISS ULTRA 55, Germany). The transmission electron microscope (JEM-2000FX, Japan) equipped with a EDX detector (NORAN-VOYAGER, USA) was used to examine the components of the precipitates of cyclically heat treated specimens for both routes. In order to determine the mechanical properties, billets for tensile and toughness tests were finished into standard tensile specimens with $25 \mathrm{~mm}$ gauge and Charpy-U notch impact specimens after being heat treated, respectively. The corresponding standards referred to GB/T228-2010 and GB/T229-2007. The standard tensile test
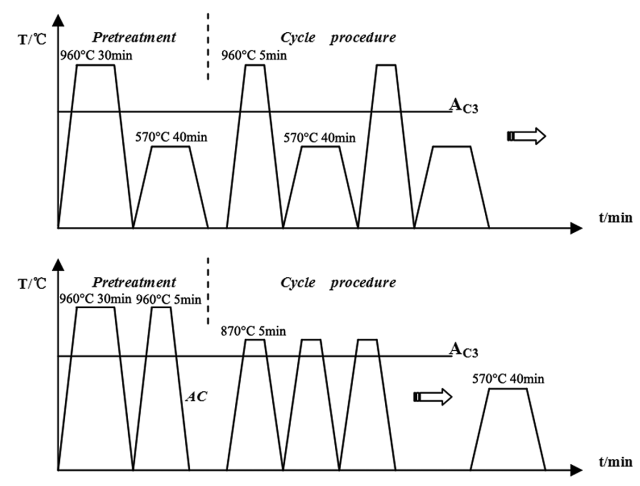

Figure 1. Two cyclic heat treatment routes used in the study. (a) Route 1, traditional route; (b) Route 2, new-designed route. and impact test were carried out on servohydraulic universal testing machine (CMT4105, China) and pendulum impact testing machine (ZBC2452-B, China) at room temperature.

\section{Results and Discussion}

\subsection{Refinement of grain and the corresponding mechanisms}

The application of cyclic heat treatments resulted in significant grain refinement in this study. However, as a result of different mechanisms the grain refinements of tested steel showed remarkably different features for two routes: (a) the variation of mean grain size with cyclic numbers and (b) the degree of grain refinement.

\subsubsection{Route 1}

The grain morphologies of pretreated specimen ( 0 -cycle) and cyclically heat-treated specimens for Route 1 are shown in Figure 2a-f. Figure 3 illustrates the relationship between mean grain size and cyclic numbers. Following pretreatment the grains of tested steel were discontinuously coarsened $(\sim 25 \mu \mathrm{m})$ shown in Figure 2a. Generally, the interpretation on variation of austenitic grain size is mainly based on Zener's "model of partical pinning of grain boundaries" as well as the relevant modifications ${ }^{9}$ for microalloyed steel. Thereby, after a long-duration solution treatment some precipitated particles may be ripening and coarsened which would cause deterioration of pinning effect. Subsequently, the isolated grains getting rid of pinning grew rapidly at the expense of the surrounding grains (Figure 2a shows that coarse grains have been surrounded by the fine grains), i.e. abnormal growth. The coarse grains became coarser and the fine grains became finer with the prolongation of soaking time. On execution of 1-cycle the mean grain size drastically reduced to $13.9 \pm 1.5 \mu \mathrm{m}$ (Figure $2 \mathrm{~b}$ ). It reduced a little and remained almost constant following subsequent cycles and reached $12.7 \pm 0.7 \mu \mathrm{m}$ up to 7 -cycle (Figure 2c-f).

To investigate the grain refinement mechanism for Route 1 , the pretreated specimen was soaked at $960{ }^{\circ} \mathrm{C}$ for 70 seconds followed by rapid cooling in ice water to retain the grain morphologies of prior austenite as shown in Figure 4a. In Figure 4a, the black area denotes the partially dissolved cementite (PDC), while the grey area denotes nucleated austenite grain (NAR). Figure $4 \mathrm{~b}$ and Figure $4 \mathrm{c}$ are the enlargements marked by arrow in Figure 4a.

For Route 1, the cementite particles precipitated dispersedly during the last tempering acted as the nucleation sites of austenite grains for next cycle. Following the short-duration holding an immediate quenching was done to retain fine austenitic grains, which resulted in the whole grain refinement. During the short-duration soaking there were two patterns for the nucleation of prior austenite grains. Pattern I: the dissolution of cementite particle occurred at one side of cementite/matrix interface at which austenite grains would nucleate due to the relatively carbon-riched

Table 1. Composition analysis of tested steels (wt $\%)$.

\begin{tabular}{ccccccccccc}
\hline $\mathbf{C}$ & $\mathbf{S i}$ & $\mathbf{M n}$ & $\mathbf{P}$ & $\mathbf{S}$ & $\mathbf{C r}$ & $\mathbf{N i}$ & $\mathbf{C u}$ & $\mathbf{V}$ & $\mathbf{T i}$ & $\mathbf{N}$ \\
\hline 0.34 & 0.26 & 0.74 & 0.0080 & 0.0055 & 0.25 & 0.30 & 0.0090 & 0.020 & 0.044 & 0.007 \\
\hline
\end{tabular}



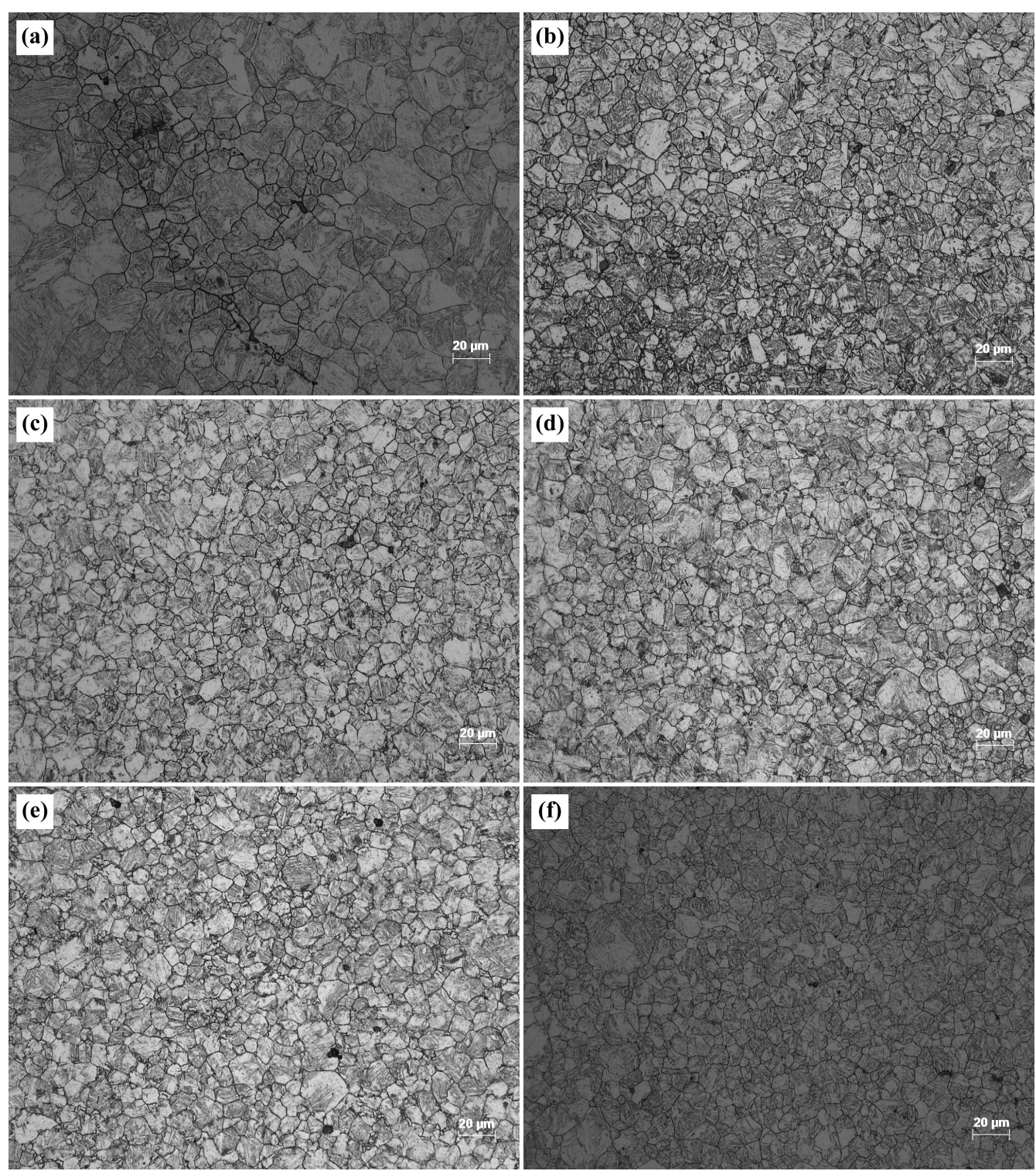

Figure 2. Grain morphologies $(\times 500)$ of pretreated specimen and cyclically heat treated specimens for Route 1: (a) pretreated $(0$-cycle); (b)1-cycle; (c) 2-cycle; (d) 3-cycle; (e) 4-cycle; (f) 7-cycle.

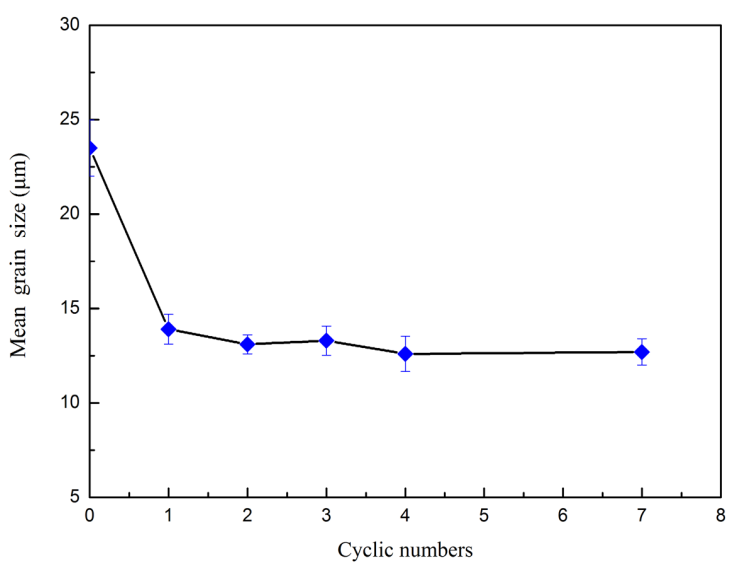

Figure 3. Variation of mean grain size with cyclic numbers for Route 1. matrix, i.e. unilateral (one-side) nucleation (Figure 4b). It coule be seen that the shape of cementite particle became irregular due to the one-side dissolution. Pattern II shown in Figure 4c: since the uniform dissolution of cementite particle, the surrounding matrix was carbon-riched that made austenite grain nucleate and grow by encompassing cementite particle border, i.e. encompassing nucleation. Meanwhile, the cementite particle remained sub-circular as a result of uniform dissolution per se.

\subsubsection{Route 2}

The grain morphologies of pretreated specimen ( 0 -cycle) and cyclically heat-treated specimens for Route 2 are shown in Figure 5a-f. The relationship between mean grain size and cyclic numbers is shown in Figure 6. The mean grain size of pretreated specimen reached $9.4 \pm 0.6 \mu \mathrm{m}$ far lower than 


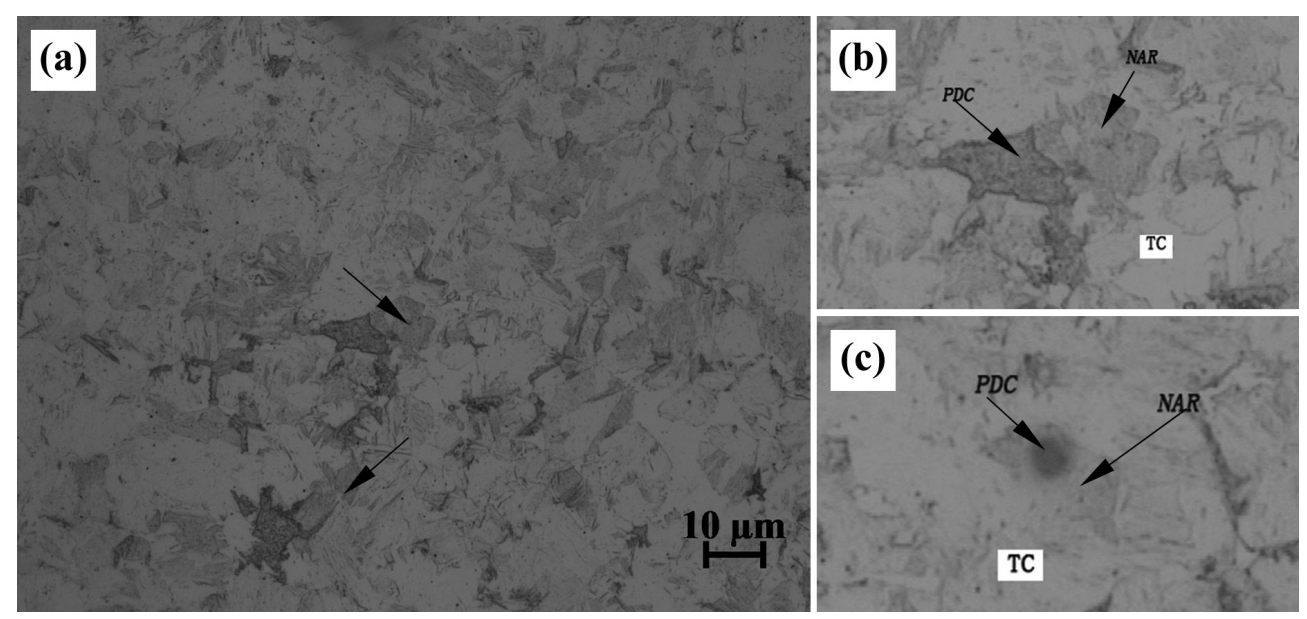

Figure 4. Optical microstructure of the specimen soaked at $960^{\circ} \mathrm{C}$ for 70 seconds followed by rapid cooling in ice water after pretreatment. PDC, Partially dissolved cementite; NAR, Nucleated austinite region; TC, tempered sorbite.
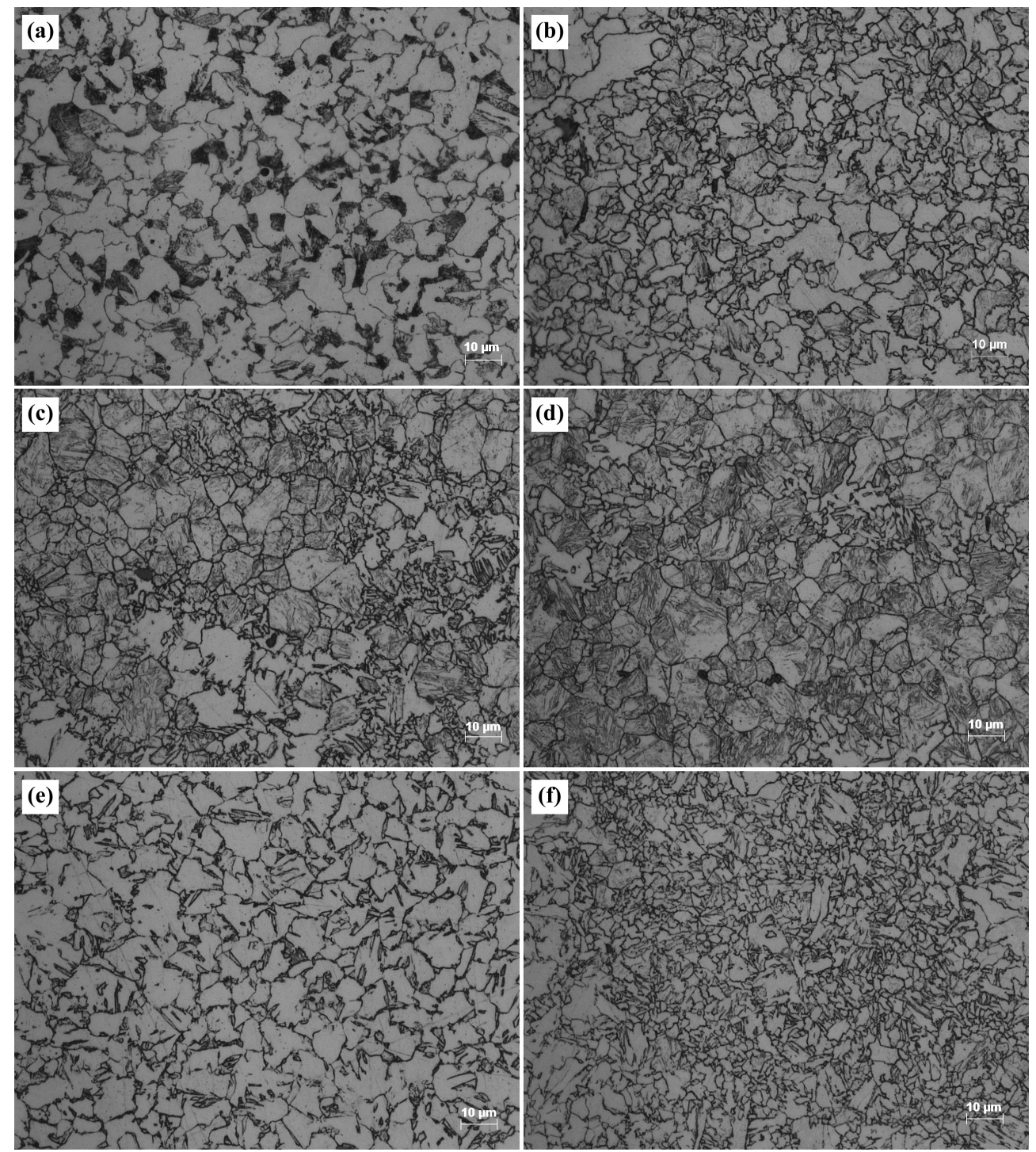

Figure 5. Grain morphologies $(\times 1000)$ of pretreated specimen and cyclically heat treated specimens for Route 2 : (a) pretreated $(0$-cycle); (b) 1-cycle; (c) 2-cycle; (d) 3-cycle; (e) 4-cycle; (f) 7-cycle. 
that for Route 1 (Figure 5a). The probable reason is that the pretreatment within Route 2 was ended with normalizing belonging to diffusional transformations which could effectively refine grain structure. On execution of 1-cycle the mean

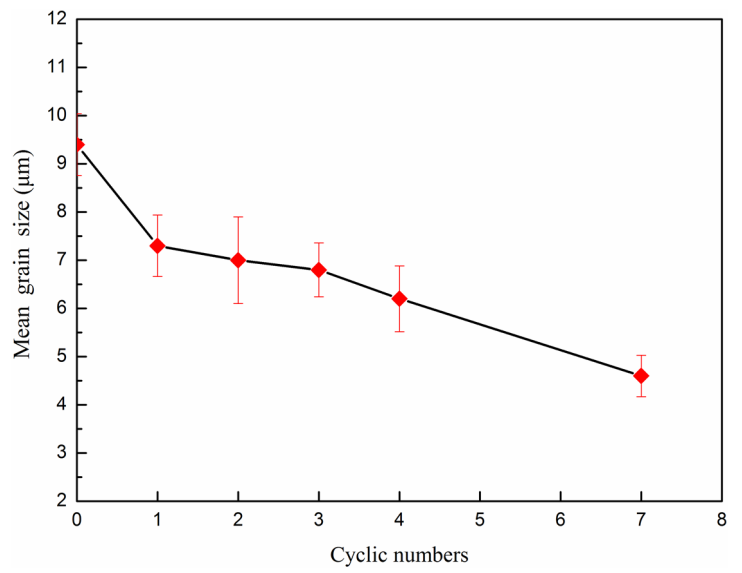

Figure 6. Variation of mean grain size with cyclic numbers for Route 2. grain size reduced to $7.3 \pm 0.6 \mu \mathrm{m}$. It reduced continuously with increasing of cyclic numbers and reached $4.6 \pm 0.4 \mu \mathrm{m}$ up to 7-cycle (Figure 5b-f). In order to investigate the grain refinement mechanism for Route 2, cyclically heat-treated specimens (without being tempered) were examined in SEM so as to observe the microstructural modifications.

0-cycle: The current microstructure of hypo-eutectoid steel consisted of proeutectoid ferrite and pearlite areas (Figure 7a) due to the previous normalizing. Compared with ferrite, the austenite is relatively carbon-riched. The normalizing treatment in this work aims to restrict the regions of austenitic nucleation and growth within prior pearlite areas as the carbon mainly exists in pearlite in the form of cementite lamellae.

1-cycle: Figure $7 \mathrm{~b}$ shows that the lamellar cementite was dissolving during the quenching soaking of 1-cycle. The short-duration (less than $5 \mathrm{~min}$ ) at $870{ }^{\circ} \mathrm{C}$ was to impede the rapid dissolution of cementite lamellae and keep the dissolved carbon at low levels in prior pearlite areas. Therefore, the excessive growth of austenite grains would be refrained. Meanwhile the presence of undissolved cementite lamellae is reported to impede the growth of austenite grains ${ }^{10}$.
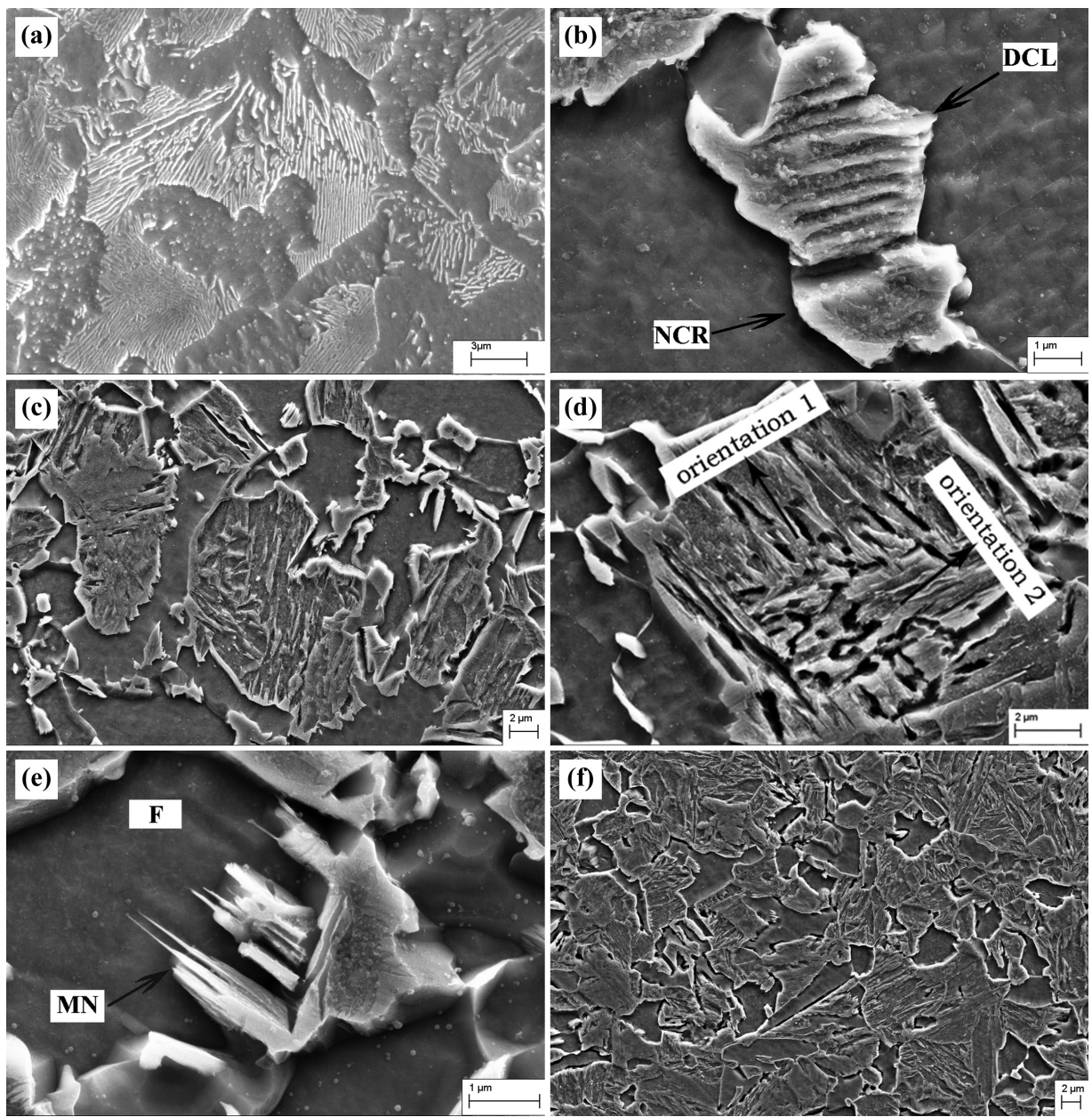

Figure 7. SEM images of specimens subjected to different heat treatment cycles without being tempered: (a) pretreated (0-cycle); (b)1-cycle, DCL: dissolving cementite lamellae, NCR: no-cementite region; (c) 2-cycle; (d) 3-cycle; (e) 4-cycle, F: ferrite, MN: martensite needles; (f) 7-cycle. 
2-cycle: The massive nucleation and growth of austenite grains emerged since 2-cycle, however, merely confined to the prior pearlite regions. A real pearlitic lamellar structure is never perfect. The defect enriched lamellar fault regions of higher curvature, such as kinks, striations, holes, fissures and terminations always exist in cementite lamellae ${ }^{11}$. These regions of higher curvature possess higher chemical potential, thus the dissolution of cementite lamellae preferentially occurs at these fault sites. Undoubtedly, as one of the most abundant defects within cementite lamellae, the terminations connected with pearlitic boundaries would first be dissolved during quenching soaking that caused the adjacent matrix carbon-riched. Furthermore, as potential nucleation sites, pearlitic boundaries give priority to the nucleation and growth of austenitic grains corroborated by the locations of acicular martensite in prior pearlite regions (Figure 7c). Actually, other internal defects also provide such possibilities.

3-cycle: more austenite grains appeared in prior pearlite regions. Precisely because of this, the martensitic clusters with different orientations (orientation 1 and orientation 2 in Figure 7d) collided drastically after forced cooling, causing the fragmentation of clusters considered as a source of defects. As high-energy regions these defects provide more nucleation sites for subsequent cycles, which promotes the further grain refinement within prior pearlite regions.

4-cycle to 7-cycle: prior to 3-cycle the grain refinement was concentrated in the prior pearlite regions, i.e. local refinement. Since 4-cycle, some austenite grains begun to nucleate at prior pearlite boundaries and grow towards proeutectoid ferrite areas, which is corroborated by the locations of martensite needles (MN) in Figure 7e. Therefore, the grain refinement was achieved on the whole accompanied by the consecutive decrease of ferrite proportion. Compared with the pretreated specimen (Figure 7a), it is intuitively observed that the ferrite proportion of tested steel became quite low after 7-cycle (Figure 7f).

\subsection{Precipitate analysis}

The probable precipitated particles in as-cast steel consist of $\operatorname{Ti}(\mathrm{C}, \mathrm{N})$ and $\mathrm{V}(\mathrm{C}, \mathrm{N})$ in view of the chemical composition shown in Table 1 . These precipitated particles are usually formed in three stages ${ }^{12}$ : Type 1 in the liquid phase and during or after solidification, Type 2 in austenite after solution treatment and during hot deformation, and Type 3 during the austenite to ferrite transformation. According to the solubility diagram by Nagata et al. ${ }^{13}$ as well as the precipitation order of carbonitrides and the content of each element shown in Table 1, the major fraction of TiN precipitated in austenite, thus the other precipitates would also precipitate in solid. Therefore, in this work the precipitates formed in liquid (which not only have a minor fraction, but also are too stable and large to make effective pinning for grain boundaries and dislocations ${ }^{12}$ ) weren't taken into consideration.

According to the solubility products taken from the work of Narita et al. ${ }^{14-16}$ and the formula of effective Ti content, i.e. Equations 1-5, it can be calculated that the solubility temperatures for precipitates in tested steel are $1499{ }^{\circ} \mathrm{C}$ for TiN, $990{ }^{\circ} \mathrm{C}$ for $\mathrm{TiC}$ and $800{ }^{\circ} \mathrm{C}$ for $\mathrm{VC}$, respectively. The absence of $\mathrm{VN}$ is mainly due to the lack of $\mathrm{N}$ atoms, all of which are in the form of TiN based on theoretical calculation.
In addition, the large-size TiN particles (micron levels) precipitated in austenite would not re-precipitate in the subsequent heat treatments due to the relatively lower test temperature at which the TiN particles couldn't be dissolved. After a synthetic analysis of the above, the only two possible precipitates, namely TiC and VC, are discussed in this work.

$\lg [\mathrm{Ti}][\mathrm{N}]_{\gamma}=5.4-15790 / \mathrm{T}$

$\lg [\mathrm{Ti}][\mathrm{C}]_{\gamma}=2.75-7000 / \mathrm{T}$

$\lg [\mathrm{V}][\mathrm{N}]_{\gamma}=3.46-8830 / \mathrm{T}$

$\lg [\mathrm{V}][\mathrm{C}]_{\gamma}=6.72-9500 / \mathrm{T}$

$\left[\mathrm{w}_{\mathrm{TiC}}\right]_{\mathrm{TiC}}=\left[\mathrm{w}_{\mathrm{TiC}}\right]_{\text {total }}-3.42\left[\mathrm{w}_{\mathrm{N}}\right]_{\mathrm{TiN}}-3\left[\mathrm{w}_{\mathrm{S}}\right]_{\mathrm{Ti}_{4} \mathrm{C}_{2} \mathrm{~S}_{2}}$

Figure 8a shows the morphology and corresponding EDX analysis of precipitates for the specimen only subjected to solution treatment $\left(960^{\circ} \mathrm{C}, 30 \mathrm{~min}\right)$. As the solution temperature lied between the solubility temperatures of TiC and $\mathrm{VC}$, the major component of precipitates was TiC also confirmed by EDX measurement. After tempering there were two peaks in EDX where the peak of Ti was much higher than that of $\mathrm{V}$ (Figure $8 \mathrm{~b}$ ), indicating that the prior TiC particles acted as the preferential nucleation sites of VC during tempering. The two carbides show the extensive mutual solubilities arising from the fact that they have similar fcc structures and have very similar lattice parameters ${ }^{17}$. As a combination of TiC and VC such carbide could be recognised as complex carbide as shown in Figure 8b. Following several cycles the component and amount of complex carbides essentially remained unchanged in tested steel for Route 1. Different from Route 1, the pretreatment of Route 2 ended up with normalizing which resulted in the interphase precipitation of VC during gamma-alpha transformation. On execution of cycle procedure the complex carbides similar to that of Route 1 would emerge in tested steel.

The variations of mean complex carbide size with cyclic numbers for Route 1 \& Route 2 are presented in Figure 9 (two solid lines), respectively. It can be seen that there is no regularity between the two parameters probably ascribed to the repeated re-dissolution and precipitation of $\mathrm{VC}$ within complex carbides on execution of each cycle for Route 1. For Route 2, however, the mean complex carbide size increased monotonically with increasing of cyclic numbers. The possible reason is that, with cyclic numbers the cumulative quenching soaking time increased continuously, which caused the amount of dissolved vanadium increasing and led to more precipitated VC during the final tempering. In addition, the mean complex carbide size of each cycle for Route 2 is smaller than that for Route 1 (Figure 9).

\subsection{Mechanical properties}

In this work, the evaluation of mechanical properties are based on the UTS (ultimate tensile strength) and $\mathrm{A}_{\mathrm{KU}}$ (Charpy-U notch impact absorbing energy) of tested steel. The variations of UTS and $A_{K U}$ with increasing of cyclic numbers and the corresponding mechanisms for both routes are studied. 

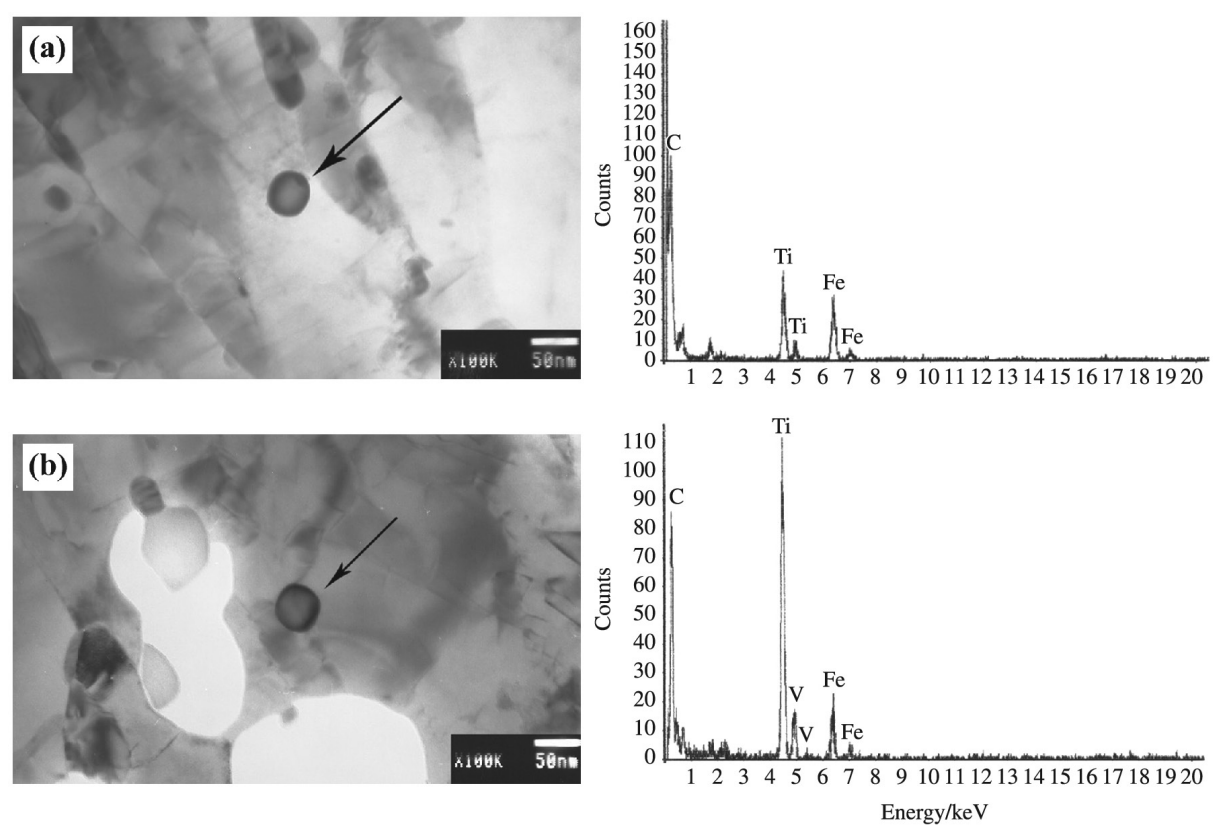

Figure 8. precipitate morphology and EDX analysis of the tested steel subjected to: (a) solution treatment; (b) solution and tempering (pretreatment) for Route 1.

\subsubsection{Route 1}

The relationship between UTS and cyclic numbers is shown in Figure 10. Generally, for steels without any form of deformation, the tensile strength is higher if the mean grain size is finer. For Route 1 the mean grain size initially reduced at 1-cycle and thereafter remained almost constant in subsequent cycles (Figure 3), while the UTS decreased continuously with cyclic numbers. Apparently, fine grain strengthening is no longer the major strengthening mechanism for Route 1. From the perspective of specific process, with cyclic numbers the cumulative time of tempering increased sharply compared with that of quenching (for Route 1 each cycle consisted of 5 min quenching soaking and $40 \mathrm{~min}$ tempering soaking). Therefore, the continuous decrease of UTS may be ascribed to the accumulation effect of temper softening.

The relationship between $\mathrm{A}_{\mathrm{KU}}$ and cyclic numbers is shown in Figure 11. Similar with UTS, the impact absorbing energy is higher if the mean grain size is finer and vice versa. The variation of $\mathrm{A}_{\mathrm{KU}}$ with cyclic numbers is evidently inconsistent with such regularity for Route 1 . The pinning of precipitated particles resulted in the abnormal growth of coarser grains and the accompanying consumption of finer grains in tested steel corroborated in Section 3.1.1 (Figure 2a). Such a 'duplex structure' led to the ununiformity of grain size distribution which might affect the impact toughness. Given this, relative differences (RD) of grain sizes shown in Equation 6 are used in the present study to establish the abnormal grain size criterion ${ }^{5}$, in which GS is the mean grain size of the distributions shown in Equation $7 \sigma$ is the standard deviation of all statistical grain sizes.

$\mathrm{GS}_{\mathrm{abnormal}}=\mathrm{GS}+2 \sigma$

$\mathrm{RD}=\frac{\mathrm{GS}_{\mathrm{abnormal}}-\mathrm{GS}}{\mathrm{GS}}$

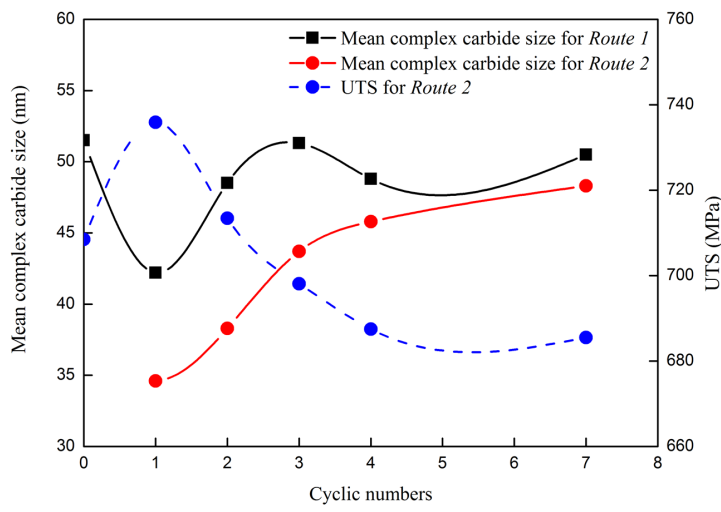

Figure 9. Variations of mean complex carbide size for Route $1 \&$ Route 2 and UTS for Route 2 with cyclic numbers.

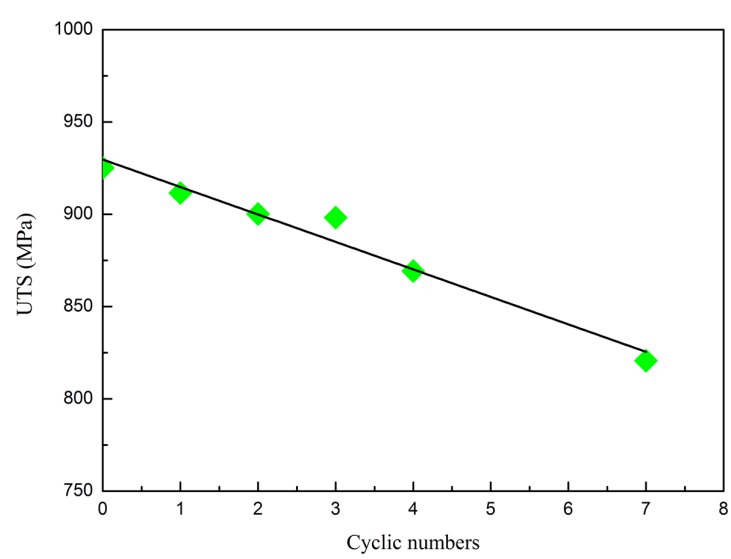

Figure 10. Ralationship between UTS and cyclic numbers of tested steel for Route 1. 
The variation of RD with cyclic numbers is given in Table 2 and graphically presented in Figure 11 ( 0 - 5 cycles). The RD of each cycle is less than that of pretreatment (0-cycle), indicating that the cyclic heat treatment could homogenize the grain size distributions to certain extent. However, RD fluctuates continuously with increasing of cyclic numbers, not in a manner of monotonic change. Moreover, the RDs of even number cycles are less than that of odd number cycles. Remarkably, $A_{\mathrm{KU}}$ also shows a continuous fluctuation strictly corresponding to RD for each cycle, i.e., $\mathrm{A}_{\mathrm{KU}}$ is higher when $\mathrm{RD}$ is relatively lower (at even number cycles) and vice versa. Therefore, the $A_{\mathrm{KU}}$ of tested steel was mainly associated with the uniformity of grain size distribution and reached the maximum (124 J) at 4-cycle for Route 1.

\subsubsection{Route 2}

The UTS of tested steel reached the maximum $(736 \mathrm{MPa})$ at 1-cycle and then gradually decreased with cyclic numbers for Route 2 as shown in Figure 9 (the dash line). The increase of UTS at 1-cycle was due to the significant decrease of mean grain size (Figure 6). Since then the mean grain size decreased with cyclic numbers, however, UTS showed a downward trend. Obviously, fine grain strengthening is no longer the major strengthening mechanism of tested steel after 1-cycle. On the other hand, with cyclic numbers the cumulative quenching soaking time was prolonged that led to the increasing solid solution content of alloy elements for Route 2, thus the UTS would increase with cyclic numbers in terms of the solid solution strengthening. But the opposite is the case. Therefore, the effect of precipitated particles (complex carbides) on UTS, i.e. precipitation strengthening, should be taken into consideration.

In this work, given the mean complex carbide size (Figure 9) the precipitation strengthening mechanism is in Orowan mode, that is, UTS is higher if the mean complex carbide size is finer under the condition of unchanged amount of complex carbides (section 3.2). In addition, with increasing of cyclic numbers (quenching times) the dislocation density would increase probably due to the accumulation of thermal stress and transformation stress during the repeated oil cooling, and the dislocation configurations gradually transformed from tangles to networks (Figure 12). Therefore, the complex carbides had a pronounced effect on UTS for Route 2. It is evident from Figure 9 that the relationship between mean complex carbide size (Route 2) and cyclic numbers strictly follows the Orowan mode. This implies that the precipitation strengthening may be the primary strengthening mechanism for Route 2.

Figure 13 shows the variations of $\mathrm{A}_{\mathrm{KU}}$ and $\mathrm{RD}$ with cyclic numbers for Route 2. Different from Route 1, there is little relevance between $\mathrm{A}_{\mathrm{KU}}$ and $\mathrm{RD}$ especially among 1-4 cycles. Thereby the variation of $\mathrm{A}_{\mathrm{KU}}$ should be analyzed on the basis of the microstructural evolution during cycle procedure for Route 2 (section 3.1.2). Prior to 3-cycle, the increase of $\mathrm{A}_{\mathrm{KU}}$ is attributed to the local refinement achieved by the nucleation and growth of austenite grains within prior pearlite regions. Meanwhile, there is no change of the proportion of proeutectoid ferrite beneficial to $A_{\mathrm{KU}}$ of tested steel as "softer phase". Although the mean grain size continued declining since 4-cycle, $\mathrm{A}_{\mathrm{KU}}$ decreased with cyclic numbers. The probable reason is that some austenite grains that nucleated at prior pearlite boundaries begun to grow towards the interior of proeutectoid ferrite (Figure 7e),

Table 2. The value of RD for different cyclic numbers (Route 1).

\begin{tabular}{cc}
\hline Cyclic numbers & Value of RD (relative differences) \\
\hline 0 (pretreated condition) & 0.8945 \\
1 & 0.8155 \\
2 & 0.5957 \\
3 & 0.8263 \\
4 & 0.7060 \\
5 & 0.8387 \\
\hline
\end{tabular}

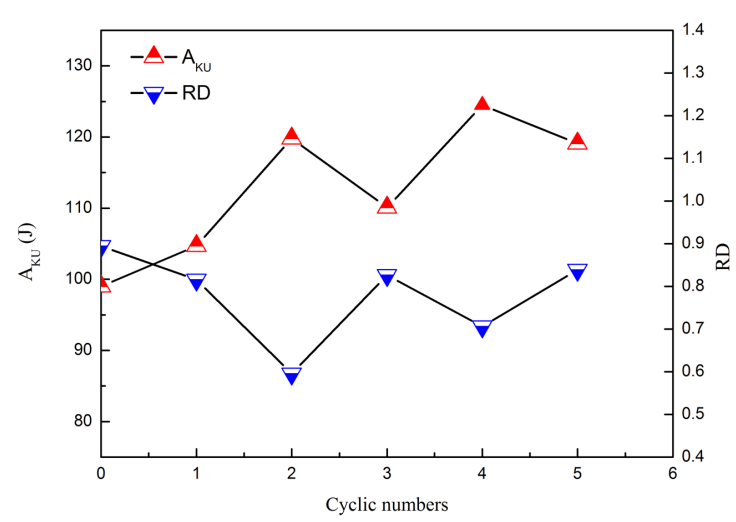

Figure 11. Trendline of $A_{K U}$, RD value with cyclic numbers for Route 1.

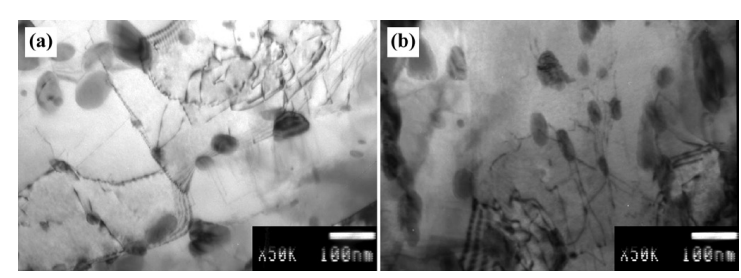

Figure 12. Precipitate and dislocation configurations of tested steel for Route 2: (a) 1-cycle; (b) 7-cycle.

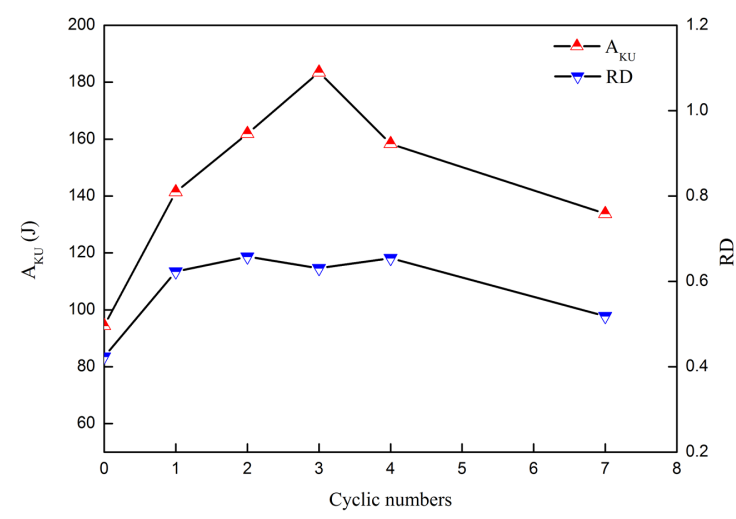

Figure 13. Trendline of $A_{K U}, R D$ value with cyclic numbers for Route 2. 
which invaded the ferrite regions and then resulted in the gradual decrease of $\mathrm{A}_{\mathrm{KU}}$ up to 7-cycle. Thus, as a result of the joint influence of mean grain size and proeutectoid ferrite proportion for Route 2, the $\mathrm{A}_{\mathrm{KU}}$ underwent a process of increasing and then decreasing with cyclic numbers and reached the maximum $(183 \mathrm{~J})$ at 3 -cycle.

\section{Conclusions}

In this work, the effects of two different cyclic heat treatments (traditional route and new-designed route, named as Route 1 and Route 2) on microstructure and mechanical properties of Ti-V microalloyed steel were investigated. The conclusions can be drawn as follows:

(1) For Route 1, the grain refinement reached the highest level at 1-cycle with mean grain size of $\sim 13.9 \mu$ m reduced by nearly $45 \%$ compared with that of pretreated specimen, and then mean grain size almost remained constant on execution of subsequent cycles. For Route 2, following pretreatment the mean grain size reduced to $\sim 9.4 \mu \mathrm{m}$ and thereafter decreased continuously with cyclic numbers, and finally reached $\sim 4.6 \mu \mathrm{m}$ at 7 -cycle reflecting a significant grain refinement.

(2) For Route 1, the cementite particles precipitated dispersedly during the last tempering acted as the nucleation sites of austenite grains for next cycle. During the short-duration

\section{References}

1. Grange RA. Strengthening steel by austenite grain refinement. ASM Trans Quart. 1966; 59(1):26-48.

2. Smoljan B. An analysis of combined cyclic heat treatment performance. Journal of Materials Processing Technology. 2004; 155:1704-1707. http://dx.doi.org/10.1016/j.jmatprotec.2004.04.121.

3. Saha A, Mondal DK, Biswas K and Maity J. Microstructural modifications and changes in mechanical properties during cyclic heat treatment of $0.16 \%$ carbon steel. Materials Science and Engineering A. 2012; 534:465-475. http://dx.doi.org/10.1016/j. msea.2011.11.095.

4. Wang JN, Yang J, Xia QF and Wang Y. On the grain size refinement of TiAl alloys by cyclic heat treatment. Materials Science and Engineering A. 2002; 329-331:118-123. http:// dx.doi.org/10.1016/S0921-5093(01)01543-X.

5. Fernández J, Illescas S and Guilemany JM. Effect of microalloying elements on the austenitic grain growth in a low carbon HSLA steel. Materials Letters. 2007; 61(11-12):2389-2392. http:// dx.doi.org/10.1016/j.matlet.2006.09.021.

6. Fernández AI, Uranga P, López B and Rodriguez-Ibabe JM. Dynamic recrystallization behavior covering a wide austenite grain size range in $\mathrm{Nb}$ and $\mathrm{Nb}-\mathrm{Ti}$ microalloyed steels. Materials Science and Engineering A. 2003; 361(1-2):367-376. http:// dx.doi.org/10.1016/S0921-5093(03)00562-8.

7. Prikryl M, Kroupa A, Weatherly GC and Subramanian SV. Precipitation behavior in a medium carbon, Ti-VN microalloyed steel. Metallurgical and Materials Transactions A: Physical Metallurgy and Materials Science. 1996; 27A(5):1149-1165. http://dx.doi.org/10.1007/BF02649854.

8. Misra RDK, Nathani H, Hartmann JE and Siciliano F. Microstructural evolution in a new $770 \mathrm{MPa}$ hot rolled $\mathrm{Nb}-\mathrm{Ti}$ microalloyed steel. Materials Science and Engineering A. 2005; 394(1-2):339-352. http://dx.doi.org/10.1016/j.msea.2004.11.041. quenching soaking there were two patterns for the nucleation of prior austenite grains, i.e., unilateral (one-side) nucleation and encompassing nucleation. For Route 2, the refinement mechanism is divided into two parts, i.e., the local refinement concentrated within prior pearlite regions prior to 3-cycle and the overall refinement that some austenite grains begun to grow towards proeutectoid ferrite areas since 4-cycle.

(3) Actually the precipitates in cyclically heat-treated specimens were the complex carbides composed by $\mathrm{TiC}$ and $\mathrm{VC}$, the amount of which essentially remained unchanged during the cycle procedure for both routes. The mean complex carbides size varied irregularly with cyclic numbers for Route 1. For Route 2, however, the mean complex carbide size increased monotonically with cyclic numbers.

(4) For Route 1, UTS decreased continuously with cyclic numbers as a result of the accumulation effect of temper softening. The $\mathrm{A}_{\mathrm{KU}}$ was mainly associated with the uniformity of grain size distribution (or RD) and reached the maximum (124 J) at 4-cycle. For Route 2, UTS reached the maximum at 1-cycle and then gradually decreased with cyclic numbers. As a result of the joint influence of mean grain size and proeutectoid ferrite proportion, $\mathrm{A}_{\mathrm{KU}}$ underwent a process of increasing and then decreasing with cyclic numbers and reached the maximum $(183 \mathrm{~J})$ at 3-cycle twice that of pretreated specimen.

9. Manohar PA, Ferry M and Chandra T. Five decades of Zener equation. ISIJ International. 1998; 38(9):913-924. http://dx.doi. org/10.2355/isijinternational.38.913.

10. Kumar R. Physical metallurgy of iron and steel. Bombay: Asia Publishing House; 1968.

11. Saha A, Mondal DK and Maity J. Effect of cyclic heat treatment on microstructure and mechanical properties of $0.6 \mathrm{wt} \%$ carbon steel. Materials Science and Engineering A. 2010; 527(1617):4001-4007. http://dx.doi.org/10.1016/j.msea.2010.03.003.

12. Gündüz $\mathrm{S}$ and Cochrane RC. Influence of cooling rate and tempering on precipitation and hardness of vanadium microalloyed steel. Materials \& Design. 2005; 26(6):486-492. http://dx.doi. org/10.1016/j.matdes.2004.07.022.

13. Nagata MT, Speer JG and Matlock DK. Titanium nitride precipitation behavior in thin-slab cast high-strength low-alloy steels. Metallurgical and Materials Transactions. A, Physical Metallurgy and Materials Science. 2002; 33A(10):3099-3110. http://dx.doi.org/10.1007/s11661-002-0294-z.

14. Narita K. Physical chemistry of the groups IVa (Ti, Zr), Va (V, $\mathrm{Nb}, \mathrm{Ta})$ and the rare earth elements in steel. ISIJ International. $1975 ; 15: 145-152$.

15. Balasubramanian K, Kroupa A and Kirkaldy JS. Experimental investigation of the thermodynamics of the Fe-Ti-C austenite and the solubility of titanium carbide. Metallurgical and Materials Transactions. A, Physical Metallurgy and Materials Science. 1992; 23(3):709-727. http://dx.doi.org/10.1007/BF02675550.

16. Morita Z, Tanaka T and Yanai T. Equilibria of nitride forming reactions in liquid iron alloys. Metallurgical Transactions. B, Process Metallurgy. 1987; 18(1):195-202. http://dx.doi. org/10.1007/BF02658444.

17. Pandit A, Murugaiyan A, Podder AS, Haldar A, Bhattacharjee $\mathrm{D}$, Chandra S, et al. Strain induced precipitation of complex carbonitrides in $\mathrm{Nb}-\mathrm{V}$ and Ti-V microalloyed steels. Scripta Materialia. 2005; 53(11):1309-1314. http://dx.doi.org/10.1016/j. scriptamat.2005.07.003. 